\title{
Madame du Deffand, Lettres (1742-1780)
}

\section{Franco Piva}

\section{(2) OpenEdition}

\section{Journals}

\section{Édition électronique}

URL : https://journals.openedition.org/studifrancesi/40748

DOI : 10.4000/studifrancesi.40748

ISSN : 2427-5856

\section{Éditeur}

Rosenberg \& Sellier

\section{Édition imprimée}

Date de publication : 1 juillet 2004

Pagination : 197

ISSN : 0039-2944

\section{Référence électronique}

Franco Piva, « Madame du Deffand, Lettres (1742-1780) », Studi Francesi [En ligne], 142 (XLVIII | I) | 2004, mis en ligne le 30 novembre 2015, consulté le 09 septembre 2021. URL : http://

journals.openedition.org/studifrancesi/40748 ; DOI : https://doi.org/10.4000/studifrancesi.40748

Ce document a été généré automatiquement le 9 septembre 2021.

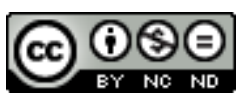

Studi Francesi è distribuita con Licenza Creative Commons Attribuzione - Non commerciale - Non opere derivate 4.0 Internazionale. 


\title{
Madame du Deffand, Lettres (1742-1780)
}

\author{
Franco Piva
}

\section{RÉFÉRENCE}

MADAME DU DEFFAND, Lettres (1742-1780). Préface de Chantal Thomas, Paris, Mercure de France («Le Temps retrouvé»), 2002, pp. 983.

1 Dans le panorama culturel et intellectuel du XVIII ${ }^{\mathrm{e}}$ siècle, Mme du Deffand occupe depuis quelques années une place et un rôle de plus en plus importants; elle n'est plus seulement l'animatrice d'un des salons les plus importants du XVIII ${ }^{\mathrm{e}}$ siècle; elle n'est pas non plus seulement cette grande dame aveugle, rongée par l'ennui, qui avait cherché un peu égoistiquement à s'attacher le jeune Horace Walpole. Elle représente un des aspects les plus typiques du XVIII ${ }^{\mathrm{e}}$ siècle, qu'elle traverse presque d'un bout à l'autre. Née en 1697 sous Louis XIV, Mme du Deffand fit son entrée dans le monde à la faveur des fastes et du libertinage de la Régence, dont elle profita abondamment. Il lui en resta cependant un goût en quelque sorte amer, qu'elle chercha à effacer d'abord dans la vie bruyante d'un des salons les plus célèbres et recherchés de l'époque, ensuite (à partir des années Cinquante) dans une activité d'écriture qui répond moins chez elle à un besoin de créativité (elle se sentait incapable de concevoir une véritable oeuvre) qu'à la nécessité de remplir un vide, qui au fil des années se faisait de plus en plus sensible, jusqu'à se transformer en une sorte de hantise. On a souvent employé le mot d'ennui, à ce propos, Mme du Deffand l'a employé elle-aussi souvent, même s'il faut, pour ne pas se tromper, lui donner un sens et un contenu bien précis. Il constitue en tout cas la clé pour comprende son activité d'épistolière. C'est, pour cette grande dame qui avait peur de rester seule et seule avec elle-même, une façon de continuer les causeries de salon, ou si l'on préfère de remplir les vides créés par des insomnies de plus en plus longues. Il n'y a en effet, dans ces lettres aucun épenchament de coeur sinon secret, aucune sentimentalité sinon suffoquée, par discrétion ou par pudeur. Par contre, toute une galerie de silhouettes et de faits-divers vus et lus avec la lucidité qui 
caractérisait Mme du Deffand, et qui permettent de voir le XVIII siècle d'un autre point de vue et d'avoir, par conséquent, de ce siècle, dont Mme du Deffand fut une des personnalités les plus marquantes, une vision plus ample et, finalement, plus exacte parce que plus complète. La présente édition, précédée d'une Préface de Chantal Thomas qui souligne les aspects essentiels de la personnalité de Mme Du Deffand, a été établie d'après la Correspondance complète de la marquise du Deffand publiée par $\mathrm{M}$. de Lescure en deux tomes chez Henri Plon en 1865. Reprise il y a une trentaine d'années par les Slatkine Reprints, la Correspondance de Mme du Deffand restait malgré tout d'un accès assez difficile; œ n'est plus le cas maintenant, vu le choix, tout à fait appréciable, du Mercure de France de la présenter dans une collection à la portée de tous. 